\title{
Effects of thyroidectomy and thyroxine replacement on seasonal reproduction in the red deer hind
}

\author{
G. M. Anderson* and G. K. Barrell ${ }^{\dagger}$ \\ Animal and Food Sciences Division, PO Box 84, Lincoln University Canterbury, New Zealand
}

Two experiments were conducted to test whether thyroid hormones are required for the cessation of the breeding season in female red deer. In Expt 1, 16 mature hinds were allocated early in the breeding season (May) to the following groups: thyroidectomized (THX), thyroidectomized and treated with subcutaneous thyroxine implants which increased plasma tri-iodothyronine to physiological concentrations ( $\mathrm{THX}+\mathrm{T}_{4}$ ), or euthyroid controls. Plasma progesterone concentrations consistent with oestrous cyclicity were evident in all hinds during the breeding season (May-September) but after 23 September plasma progesterone concentrations became generally low $\left(<2.0 \mathrm{nmol} \mathrm{l}^{-1}\right)$ in control and $\mathrm{THX}+\mathrm{T}_{4}$ hinds. In contrast, thyroidectomized hinds not receiving thyroxine continued to exhibit circulating progesterone comparable with breeding season concentrations until the end of the experiment (late December). Nine hinds were ovariectomized or ovariectomized and thyroidectomized in May and treated with subcutaneous oestradiol-impregnated capsules, which were removed for periods of about 1 month during August, November and January, to test whether thyroid hormones are involved in the seasonal decline of LH secretion (Expt 2). In the presence of oestradiol, basal LH concentrations and episodic LH secretion were low during the non-breeding season (September-March) $(P<0.05)$. During this season, basal and GnRH-induced LH concentrations and LH pulse frequency remained similar for both groups except in the absence of oestradiol, when basal LH ( $3.1 \pm 0.8$ versus $1.3 \pm 0.5 \mathrm{ng} \mathrm{ml}^{-1}, P<0.05$ and GnRH-induced LH $\left(25.9 \pm 3.6\right.$ versus $4.7 \pm 0.4 \mathrm{ng} \mathrm{ml}^{-1}$, $P<0.001)$ concentrations were higher in thyroidectomized hinds than in euthyroid hinds, respectively. Twenty-five hinds were ovariectomized and thyroidectomized during the breeding season and treated with subcutaneous thyroxine implants at different times to identify when thyroid hormones are required to be present to suppress LH concentrations during the non-breeding season in the absence of oestradiol. Thyroxine treatment at the beginning of or during the non-breeding season was effective in suppressing plasma $\mathrm{LH}$ concentration, but this action of thyroid hormones did not occur during the breeding season. These results indicate that, in red deer hinds thyroxine is required for termination of the breeding season and that thyroid gland secretions specifically block steroid-independent inhibition of reproductive activity during the non-breeding season. This inhibitory mechanism requires thyroid hormones to be present only from around the time of the end of the breeding season for their normal expression, and they remain responsive to thyroid hormones after this period.

\section{Introduction}

Red deer (Cervus elaphus) exhibit a pronounced annual breeding cycle that is regulated by photoperiod (Simpson et al., 1983; Webster and Barrell, 1985). As with the majority of temperate ungulate species (Lincoln and Short, 1980), oestrous cyclicity in female hinds begins each year during decreasing photoperiods

*Present address: Department of Physiology, West Virginia University, Morgantown, WV 26506-9229, USA.

${ }^{\dagger}$ Correspondence.

Received 18 August 1997. and, in the absence of pregnancy, recurrent cycles of approximately 18 days occur throughout the winter (Adam et al., 1985; Jopson et al., 1990; Meikle and Fisher, 1996). However, recent evidence has shown that the physiological mechanisms underlying this annual rhythm in deer may differ from those acting in sheep, from which our understanding of seasonal reproduction in farm animals is largely derived. For example, red deer hinds exhibit marked seasonal fluctuations of plasma LH concentrations (Meikle and Fisher, 1996) and responsiveness of LH secretion to exogenous GnRH (Baker et al., 1995; Meikle and Fisher, 1996) in the absence of gonadal steroids. In gonadectomized sheep, the seasonal oscillations in these 
parameters are considerably smaller (Karsch et al., 1980; Goodman and Karsch, 1981; Pau and Jackson, 1985; Robinson et al., 1985; Brewer et al., 1995; McLeod et al, 1996) and, sometimes, undetectable (Jenkin et al., 1977; Karsch et al., 1987, 1993).

Recent observations have led to the concept that the presence of thyroid hormones is required for at least one stage of the circannual rhythm of reproduction, the transition from the breeding to the non-breeding state, in many species of bird (Goldsmith and Nicholls, 1984; Follett and Nicholls, 1985) and mammals (Vriend, 1985; Jacquet et al., 1986; Nicholls et al., 1988; Moenter et al., 1991; Shi and Barrell, 1992; Parkinson and Follett, 1994). In ovariectomized, oestradiol-treated ewes, pulse frequencies of LH (Moenter et al., 1991) and GnRH (Webster et al., 1991a) remained high throughout the non-breeding season if the animals had been thyroidectomized during the preceding breeding season. In red deer stags, thyroidectomy prevented antler casting in spring and the associated decine in testis diameter, testosterone concentration and responsiveness of the pituitary gland and testes to exogenous GnRH (Shi and BarrelI, 1992). Treatment with exogenous thyroxine $\left(\mathrm{T}_{4}\right)$ overcomes the effects of thyroidectomy in ewes (Webster et al., 1991b) and stags (Shi and Barrell, 1994). It has been suggested that the neuroendocrine mechanisms that bring about seasonal anoestrus may be responsive to thyroid hormones only during a short 'window' of time within the circannual reproductive cycle (Karsch et al., 1995). If there is such a window of responsiveness, blockade of thyroid function during the critical period might enable completely aseasonal reproduction in animals that are traditionally seasonal breeders. Support for the existence of a window of responsiveness to thyroid hormones comes from recent experiments in which a brief (60-90 days) period of exposure of thyroidectomized ewes to thyroxine just before the non-breeding season was sufficient to bring about neuroendocrine anoestrus at the appropriate time (Thrun et al., 1997). However, it remains to be tested whether the period of responsiveness continues during the non-breeding season, when inhibitory photoperiods and the endogenous reproductive rhythm may both be signalling that anoestrus should be occurring.

There have been no published reports of the effects of thyroidectomy on reproduction in female deer. Red deer hinds present a unique experimental model for studying the role of thyroid hormones on steroid-independent processes controlling LH concentrations because seasonal fluctuations in LH concentrations are much more marked in ovariectomized red deer hinds than in ovariectomized ewes. The objectives for the present study were to test whether thyroid hormones are required in female red deer for the cessation of oestrous cyclicity in spring, and to investigate whether this requirement applies to steroid-dependent or steroid-independent components of seasonal breeding regulation. A third objective was to delineate a period of thyroid hormone responsiveness in ovariectomized red deer hinds.

\section{Materials and Methods}

\section{Animals and management}

Three experiments were conducted using 50 mature red deer hinds (mean body mass at the start of the experiments:
$90.0 \pm 1.9 \mathrm{~kg}$ ). Hinds were maintained outdoors (latitude $43^{\circ} 39^{\prime} \mathrm{S}$ ) on pasture of predominantiy ryegrass and white clover at all times of the year. Ryegrass silage was fed as a supplement during winter. All procedures were approved by the Lincoln University Animal Ethics Committee.

Ovariectomy was performed aseptically by midventral laparotomy under general anaesthesia induced by $250 \mathrm{mg}$ i.v. sodium thiopentone (Pentothal, Techvet Laboratories Ltd, Auckland) after recumbency induced by $114 \mathrm{mg}$ i.m. xylazine hydrochloride (Thiazine 50, RWR Veterinary Products Pty Ltd, NSW). Thyroidectomy was performed as described by Shi and Barrell (1992) using sodium thiopentone and xylazine hydrochloride as above. Blood samples were collected by jugular venepuncture into $10 \mathrm{ml}$ heparinized tubes (except for intensive collection periods when blood was drawn via indwelling 14 gauge jugular catheters (Terumo, Tokyo) into $10 \mathrm{ml}$ syringes) while the hinds were restrained manually. Plasma was removed after centrifugation at $1500 \mathrm{~g}$ and stored at $-20^{\circ} \mathrm{C}$ until assayed.

\section{Experiment 1}

Sixteen mature hinds were thyroidectomized (THX, $n=7$ ), thyroidectomized and treated s.c. in the anterior neck region with $4 \times 25 \mathrm{mg}$ sodium L-thyroxine tablets (Glaxo Laboratories Ltd, Greenford, Middlesex) in May, August and November 1995 (THX $+\mathrm{T}_{4}, n=4$ ) or untreated (euthyroid control, $n=5$ ) early in the breeding season (early May 1995) to test whether the thyroid gland is required for the annual cessation of oestrous cyclicity in red deer. Blood samples were collected twice per week until the end of December for measurement of plasma progesterone concentration. Plasma total triiodothyronine $\left(\mathrm{T}_{3}\right)$ was measured approximately once per month. Plasma total thyroxine was measured in $T H X+T_{4}$ hinds immediately before and on four occasions during the 3 months after implantation of sodium L-thyroxine tablets in August to monitor the effectiveness of this treatment.

\section{Experiment 2}

Nine hinds were ovariectomized and thyroidectomized (THX, $n=4$ ) or ovariectomized only (control, $n=5$ ) in early May 1995 to test whether the thyroid gland is required for steroid-dependent or steroid-independent inhibition of reproductive activity in the non-breeding season. All hinds were treated with slow-release silicone rubber oestradiolimpregnated implants (Compudose 200, Elanco Animal Health, Auckland), cut transversely so that each hind received one third of an implant containing $8 \mathrm{mg}$ oestradiol s.c. in the right ear from June until April the next year, except for three periods of approximately I month each, beginning on I August, 31 October and 9 January, when the implants were removed to facilitate measurement of $\mathrm{LH}$ concentrations in the absence of steroid inhibition. Blood samples were collected once per week for measurement of plasma LH concentration. Once a month, $5 \mu \mathrm{g} \mathrm{GnRH} \mathrm{(LH-RH} \mathrm{acetate} \mathrm{salt,} \mathrm{Sigma} \mathrm{Chemical} \mathrm{Co.,} \mathrm{St} \mathrm{Louis,}$ $\mathrm{MO}$ ) in $1 \mathrm{ml}$ of sterile physiological saline solution was administered i.v. immediately after the weekly blood sample and a further sample was obtained exactly 10 min later to 
assess the pituitary responsiveness to $\mathrm{GnRH}$ (calculated as the plasma $\mathrm{LH}$ concentration at 10 min minus the concentration before injection). In early July (breeding season) and late October (non-breeding season), blood samples were collected at intervals of $10 \mathrm{~min}$ for $4 \mathrm{~h}$ in the presence of the oestradiol implants to determine episodic $\mathrm{LH}$ secretion. Plasma total tri-iodothyronine concentration was measured approximately once a month.

\section{Experiment 3}

Twenty-five ovariectomized hinds were allocated in June 1996 to the following treatment groups ( $n=5$ per group): (a) thyroidectomized (THX negative controls); (b) thyroidectomized and treated with sodium L-thyroxine tablets (as in Expt 1) until 2 August, about 40 days before the normal time of onset of anoestrus in cyclic hinds ( $\mathrm{THX}+$ early $\left.\mathrm{T}_{4}\right)$; (c) thyroidectomized and treated with thyroxine as above from 2 August to 21 October, about 40 days after the normal onset of anoestrus ( $\mathrm{THX}+$ mid- $\left.\mathrm{T}_{4}\right)$; (d) thyroidectomized and treated with thyroxine from 21 October to 10 February the next year ( $\mathrm{THX}+$ late $\mathrm{T}_{4}$ ); and (e) untreated (euthyroid positive controls). Blood samples were collected each week until 27 January (euthyroid and THX control hinds) or 10 February (THX $+\mathrm{T}_{4}$ hinds) 1997 for measurement of plasma LH concentration. Once a month, $5 \mu \mathrm{g}$ GnRH (LH-RH acetate salt; Sigma Chemical Co.) was administered i.v. immediately after the weekly blood sample and a further sample was obtained exactly $13 \mathrm{~min}$ later to assess the pituitary responsiveness to $\mathrm{GnRH}$ (calculated as the LH concentration at 13 min minus the concentration before injection). In July (breeding season) and November (non-breeding season, at the time when steroidindependent suppression is maximal), blood samples were collected at intervals of $10 \mathrm{~min}$ for $4 \mathrm{~h}$ to facilitate measurement of episodic LH secretion. Plasma total tri-iodothyronine was measured approximately once a month.

\section{Hormone assays}

Plasma LH concentration was measured in duplicate $100 \mu \mathrm{l}$ aliquots by heterologous radioimmunoassay, using the method described for sheep plasma by Scaramuzzi et al. (1970) and validated for red deer plasma by Kelly et al. (1982). Values are expressed in terms of the ovine standard, NIAMDD-LH-S2O. Iodinated ovine LH (NIADDK-oLH-1-2) was used as tracer and primary antiserum was NIADDK-anti-oLH-1 (AFP-192279). The sensitivity ( $95 \%$ confidence limit at $0 \mathrm{ng} \mathrm{ml}^{-1}$ ) averaged $0.37 \mathrm{ng} \mathrm{ml}^{-1}$ over the 24 assays that contributed to the results. Intra-assay coefficients of variation (CV) averaged 15.4 and $9.6 \%$, respectively, for plasma pools displacing radiolabelled LH to approximately 80 and $51 \%$ of the total bound, and interassay CVs were 19.5 and $13.8 \%$ for the same plasma pools. Deer plasma diluted serially produced a binding curve that was parallel to that of the ovine standard.

Plasma progesterone concentration was measured in triplicate $50 \mu \mathrm{l}$ aliquots by enzyme-linked immunosorbent assay (ELISA) using the method described by Elder et al. (1987). Monoclonal mouse anti-progesterone primary antiserum was purchased from Christchurch Hospital, New Zealand. Assay sensitivity averaged $0.86 \mathrm{nmol} \mathrm{l}^{-1}$ (nine separate assays involving 64 ELISA microtitre plates). Intra-assay CVs averaged 11.9 and $6.6 \%$, respectively, for plasma pools displacing thyroglobulin-conjugated progesterone-3-(O carboxymethyl) oxime to approximately 91 and $59 \%$ of the total bound, and interassay CVs were 12.8 and $20.7 \%$ for the same plasma pools. The binding curve produced by serial dilution of deer plasma was parallel to that of the progesterone standard.

Total thyroxine and total tri-iodothyronine concentrations in plasma were assayed using commercially available kits (Coat-A-Count Total T4 and Coat-A-Count Total T3, Diagnostic Products Corp., Los Angeles, CA) in duplicate 25 and $100 \mu \mathrm{l}$ aliquots, respectively. Serial dilution of deer plasma produced binding curves that were parallel to the standard curves in both assays. The sensitivity of the assays was $3.0 \mathrm{nmol} 1^{-1}$ for total thyroxine and $0.04 \mathrm{nmol} \mathrm{l}^{-1}$ for total tri-iodothyronine. Intra-assay $\mathrm{CVs}$ for a plasma pool that displaced radiolabelled thyroxine and tri-iodothyronine to 46 and $62 \%$, respectively, of the total bound were 7.9 and $10.6 \%$. When the same plasma pool was used, interassay CVs for the five tri-iodothyronine assays that contributed to these results was $12.2 \%$. Thyroxine samples were analysed in a single assay.

\section{Statistical analysis}

Hormone concentrations below the average assay sensitivity were assigned a value equal to the sensitivity. LH pulse amplitude was calculated as the peak plasma L.H concentration minus that of the preceding nadir. A pulse of $\mathrm{LH}$ during intensive sampling periods was defined as any increase in plasma concentration where (1) the concentration was high relative to pre- and post-nadir values for at least two consecutive samples, (2) the pulse peaked within two sampling intervals, (3) the increment between peak and nadir concentrations exceeded the pre- and post-nadir values by $\geq 2 \mathrm{SD}$, and (4) the peak amplitude exceeded the sensitivity of the assay (Goodman and Karsch, 1980). A significant episode of progesterone, taken as indicative of a luteal phase, was defined as two consecutive sample concentrations exceeding $2 \mathrm{nmoll}^{-1}$, since this concentration divides typical follicular and luteal phase progesterone concentrations in red deer Jopson et al, 1990; Meikle and Fisher, 1996). The termination of the breeding season for individual control hinds was taken as the date of the commencement of the last significant progesterone episode that was followed by at least six consecutive sample concentrations of $\leq 2 \mathrm{nmol}^{-1}$. For each group, the numbers of progesterone episodes in the breeding and non-breeding seasons were calculated using the mean date of termination of the breeding season from control hinds, since cycles appeared to be irregular in some thyroidectomized hinds.

The effects of treatment on plasma tri-iodothyronine concentrations over time were analysed by linear regression analysis to identify increases in concentrations. Treatment effects on plasma LH concentrations over time in Expt 2 were analysed by multivariate analysis of variance (ANOVA) for repeated measurements (basal $\mathrm{LH}$ profiles were subdivided into periods of time corresponding to the removal and replacement of oestradiol implants for repeated measures ANOVA). Data 


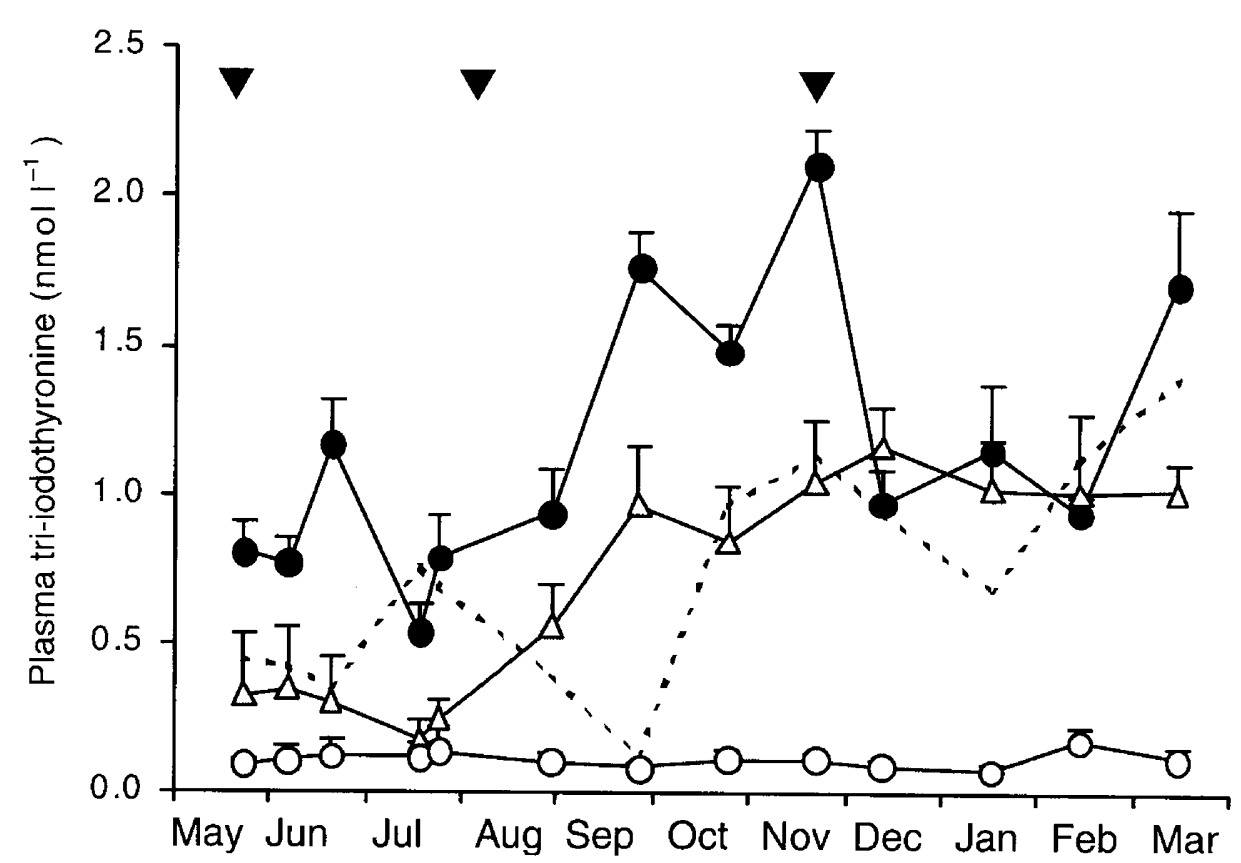

Fig. 1. Mean ( \pm SEM) plasma concentrations of total tri-iodothyronine in euthyroid control red deer hinds (,$n=10$ ), hinds thyroidectomized and treated with subcutaneous thyroxine implants $\left(\mathrm{THX}+\mathrm{T}_{4} ; \triangle, n=4\right)$ and thyroidectomized hinds $(0, n=10)$ in Expts 1 and 2. Data for hind 29 are plotted separately (-- - , see text for details). Arrowheads indicate times of thyroxine treatment ( $4 \times 25 \mathrm{mg}$ thyroxine tablets subcutaneously) for $\mathrm{THX}+\mathrm{T}_{4}$ hinds.

from each sampling time were analysed by one-way ANOVA to determine at which point the treatment effects occurred. All other treatment differences were analysed by one-way ANOVA followed, where appropriate, by means comparisons among groups using Student's t test. Hormone concentrations were $\log$ transformed (base 10) to equalize variances before statistical analysis. Mean results are presented \pm SEM.

\section{Results}

One THX hind (Hind 26) in Expt I and one THX ovariectomized hind in Expt 2 (hind 8) died early in the winter. Hind 26 had developed an abscess in one hoof that did not respond to antibiotic treatment and resulted in a decline in body condition. Cause of death was not identified in hind 8. Both animals were replaced within a few days with a recently THX hind and a long-term ( $<I$ year) THX ovariectomized hind. Breeding season data from hind 26 and its replacement were excluded from the analysis.

\section{Experiments 1 and 2: plasma tri-iodothyronine and thyroxine concentrations}

Since there was no effect of ovariectomy on mean plasma tri-iodothyronine concentration, data from Expts $I$ and 2 are presented collectively (Fig. 1). Euthyroid control hinds exhibited a seasonal increase in plasma tri-iodothyronine concentration $(P<0.001)$, reaching a peak in November (early summer). A similar pattern was observed in $\mathrm{THX}+\mathrm{T}_{4}$ hinds in Expt 1 , with plasma tri-iodothyronine concentration gradually increasing with each administration of thyroxine $(P<0.001)$. Mean plasma total thyroxine concentration in these hinds was $23.3 \pm 4.4 \mathrm{nmol} \mathrm{l}^{-1}$ immediately before implantation of thyroxine in August and, after this implantation plasma thyroxine increased to a peak value of $82.1 \pm 17.5 \mathrm{nmol} \mathrm{1^{-1 }} 1$ month later. Thereafter, concentrations gradually decreased, reaching $53.6 \pm 14.1 \mathrm{nmol} \mathrm{l}^{-1}$ by mid-November. In THX hinds, mean plasma tri-iodothyronine concentration was generally undetectable throughout the year. One THX hind (hind 29) had tri-iodothyronine concentrations in excess of $1.0 \mathrm{nmol} \mathrm{l}^{-1}$; data from this hind (which was presumed to be incompletely thyroidectomized) were excluded from the analysis and are presented separately.

\section{Experiment 3: plasma tri-iodothyronine concentration}

A seasonal increase in mean plasma concentration of total tri-iodothyronine was observed throughout the summer in euthyroid positive control hinds $(P<0.01)$, with a mean nadir of $1.06 \pm 0.19 \mathrm{nmol}^{-1}$ in spring (September) and a peak of $1.83 \pm 0.21 \mathrm{nmol} \mathrm{l}^{-1}$ in late summer (February). In contrast, mean plasma tri-iodothyronine concentration remained low $\left(<0.2 \mathrm{nmol} \mathrm{l}^{-1}\right)$ and was often undetectable throughout the year in THX control hinds. In the remaining three groups, mean tri-iodothyronine concentrations were low or undetectable in the absence of thyroxine tablets $\left(0.05 \pm 0.01 \mathrm{nmol} \mathrm{l}^{-1}\right)$ and significantly increased, albeit slightly, during periods of 


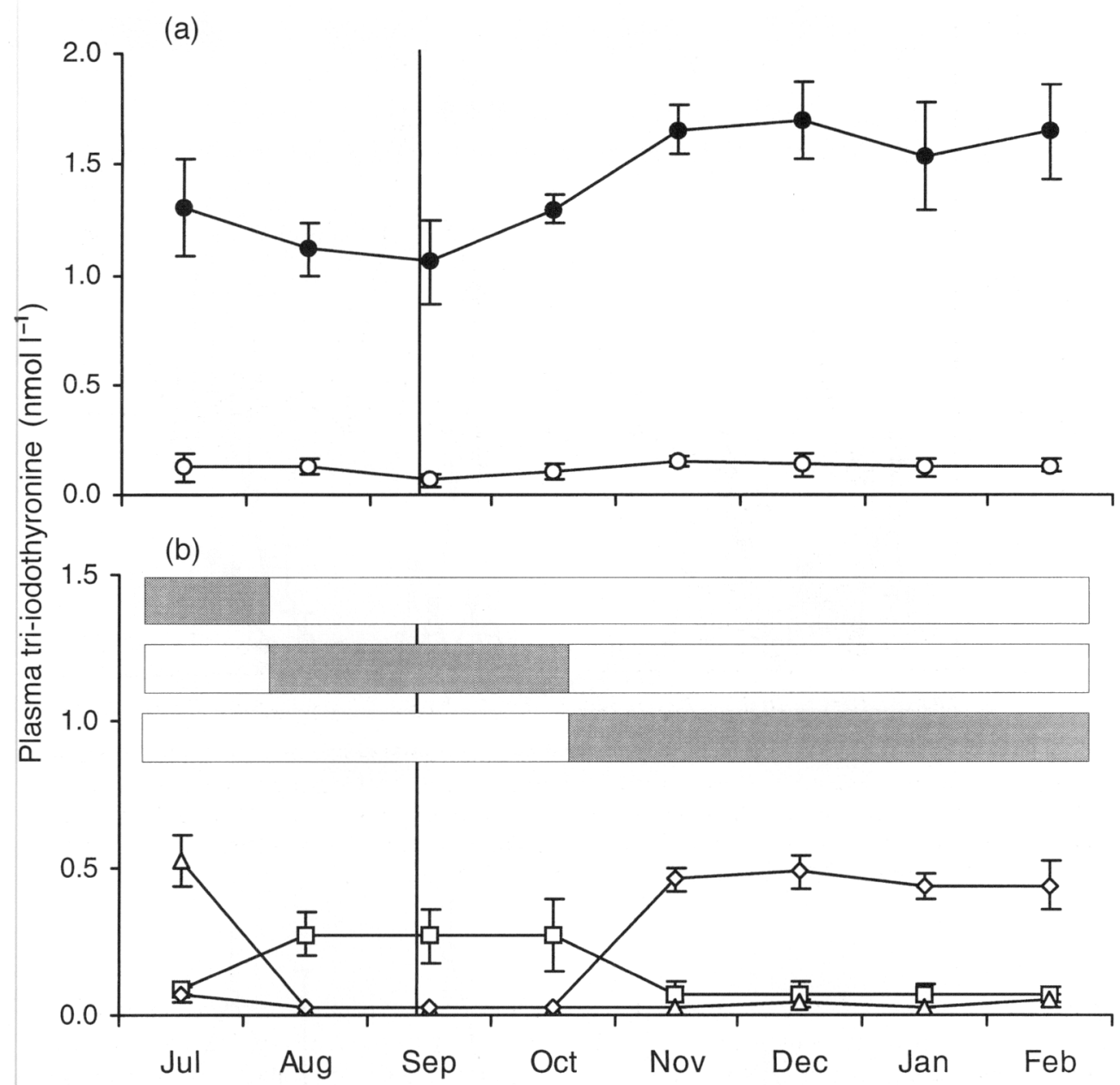

Fig. 2. Mean ( \pm SEM) plasma concentrations of total tri-iodothyronine in (a) euthyroid control ( $)$ and thyroidectomized control $(O)$ red deer hinds, and $(b)$ hinds thyroidectomized and treated with subcutaneous thyroxine implants at different times (THX + early $\mathrm{T}_{4}: \triangle ; \mathrm{THX}+$ mid- $\mathrm{T}_{4}: \square$; and THX + late $\mathrm{T}_{4}$ hinds: $\left.\diamond\right)$ $(n=5)$ in Expt 3. Shaded horizontal bars indicate times of thyroxine treatment $(4 \times 25 \mathrm{mg}$ thyroxine tablets subcutaneously) for the three $\mathrm{THX}+\mathrm{T}_{4}$ groups, respectively. Vertical lines indicate the time of the end of the breeding season for red deer hinds in New Zealand.

implantation with thyroxine tablets $\left(0.45 \pm 0.03 \mathrm{nmol} \mathrm{I}^{-1}\right.$; $P<0.05$ for THX +early $\mathrm{T}_{4}$ hinds and $P<0.001$ for $\mathrm{THX}+$ mid- $\mathrm{T}_{4}$ and $\mathrm{THX}+$ late $\mathrm{T}_{4}$ hinds) (Fig. 2).

\section{Experiment 1: plasma progesterone concentration}

All hinds exhibited significant episodes of progesterone indicative of oestrous cycles during the breeding season. $\mathrm{THX}+\mathrm{T}_{4}$ hinds exhibited fewer progesterone episodes than did control hinds $(P<0.05)$ (Table 1 ). The mean date for termination of the breeding season in control hinds was 23 September \pm 7 days. Between this date and the end of the experiment there was little evidence of further reproductive activity in control and THX $+\mathrm{T}_{4}$ hinds. One animal in the THX group that had high tri-iodothyronine concentrations (hind 29) exhibited a progesterone concentration profile similar to that of control hinds. In marked contrast, THX hinds (excluding hind 29) continued to exhibit progesterone episodes during the non-breeding season; reproductive activity continued until the
Table 1. Mean numbers of progesterone episodes during the breeding and non-breeding seasons (before and after 23 September, respectively) in female red deer thyroidectomized and treated with thyroxine (Expt 1)

\begin{tabular}{lcc}
\hline Group & $\begin{array}{c}\text { Breeding } \\
\text { season } \\
\text { (range) }\end{array}$ & $\begin{array}{c}\text { Non-breeding } \\
\text { season } \\
\text { (range) }\end{array}$ \\
\hline Control $(n=5)$ & $5.4 \pm 0.4(4-6)^{\mathrm{a}}$ & $0.8 \pm 0.4(0-2)^{\mathrm{a}}$ \\
$\mathrm{THX}+\mathrm{T}_{4}(n=4)$ & $2.8 \pm 0.5(2-3)^{\mathrm{b}}$ & $1.2 \pm 0.2(1-2)^{\mathrm{a}}$ \\
$\mathrm{THX}(n=6)$ & $4.0 \pm 0.5(3-6)^{\mathrm{ab}}$ & $3.8 \pm 0.6(2-5)^{\mathrm{b}}$
\end{tabular}

${ }^{a b}$ Within a season, values not assigned common letters are significantly different $(P<0.05)$.

THX: thyroidectomized; $T_{4}$ : thyroxine.

end of December when sampling ceased. Mean numbers of progesterone episodes detected in the breeding and non-breeding seasons are presented (Table 1 ). 


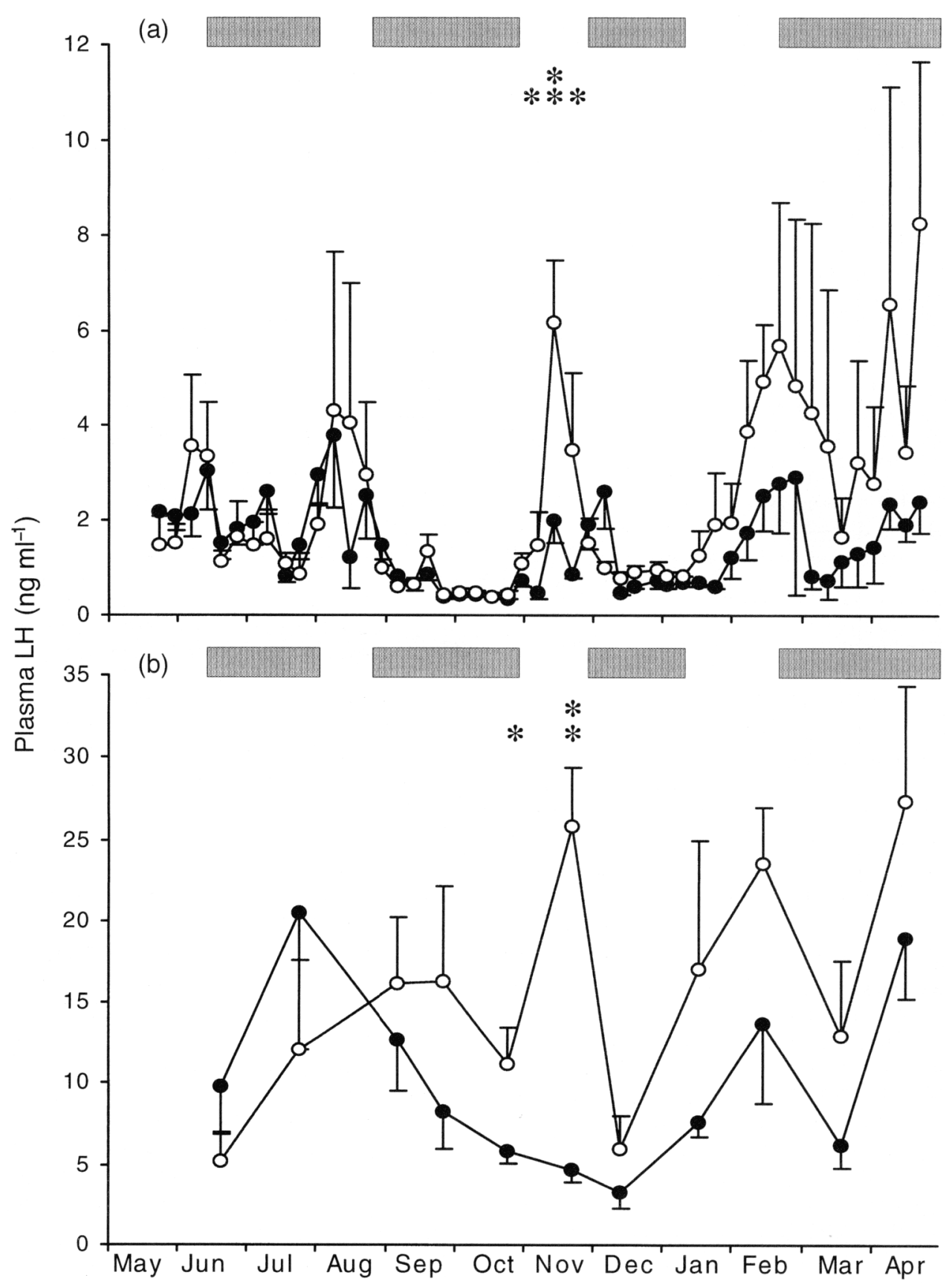

Fig. 3. (a) Mean ( \pm SEM) plasma concentrations of LH and (b) mean ( \pm SEM) plasma LH response at 10 min to $5 \mu \mathrm{g}$ GnRH i.v. in euthyroid control $(\mathbf{O}, n=5)$ and thyroidectomized $(O, n=10)$ red deer hinds in Expt 2. Periods of oestradiol treatment are indicated by shaded blocks. Vertically aligned asterisks indicate significant differences between means: $* P<0.05 ; * P<0.001$.

\section{Experiment 2: plasma LH concentration}

In control and THX hinds, plasma LH concentrations averaged $2.4 \pm 0.4 \mathrm{ng} \mathrm{ml}^{-1}$ while oestradiol implants were present during the breeding season and declined $(P<0.05)$ to $0.9 \pm 0.1 \mathrm{ng} \mathrm{ml}^{-1}$ between September and March (nonbreeding season); there was no effect of thyroidectomy $(P>0.05$ at all times). In the absence of oestradiol, plasma concentrations of $\mathrm{LH}$ were high $\left(2.6 \pm 0.3 \mathrm{ng} \mathrm{ml}^{-1}\right)$ in both control and THX hinds $(P>0.05)$ except during November, when mean concentrations were significantly lower in control than in THX hinds $\left(1.3 \pm 0.8\right.$ versus $3.1 \pm 0.8 \mathrm{ng} \mathrm{ml}^{-1}$; $P<0.001$ ) (Fig. 3). There was a seasonal pattern of $\mathrm{LH}$ response to GnRH injections in all hinds, with peak LH responses in July $\left(17.3 \pm 8.0 \mathrm{ng} \mathrm{ml}^{-1}\right)$ and in April in the following year $\left(23.2 \pm 5.7 \mathrm{ng} \mathrm{ml}^{-1}\right)$ and nadir LH response in December $\left(4.6 \pm 1.6 \mathrm{ng} \mathrm{ml}^{-1}\right)$. The LH response was similar for the two groups at all times $(P>0.05)$ except at the time oestradiol 
implants were withdrawn in November, when the response was lower for control than for THX hinds $(4.7 \pm 0.4$ versus $25.9 \pm 3.6 \mathrm{ng} \mathrm{ml}^{-1} ; P<0.001$ ) (Fig. 3). Mean numbers of LH pulses and pulse amplitude in the presence of oestradiol were similar in July $(2.6 \pm 0.7$ versus $1.8 \pm 0.6$ pulses each $4 \mathrm{~h}$; $P>0.05$, and $3.0 \pm 2.2$ versus $\left.1.3 \pm 0.4 \mathrm{ng} \mathrm{ml}^{-1} ; P>0.05\right)$ and October $(0.8 \pm 0.4$ versus no pulses each $4 \mathrm{~h} ; P>0.05$, and $0.6 \pm 0.03 \mathrm{ng} \mathrm{ml}^{-1}$ versus no pulses; $P>0.05$ ) for euthyroid and THX hinds, respectively. There was a significant decline between July and October in mean LH pulse amplitude and number of LH pulses in all hinds $(P<0.05)$.

\section{Experiment 3: plasma LH concentration}

Mean plasma LH concentrations in euthyroid control hinds were high during winter and spring (June-mid-October) and low during early summer (mid-October-December) (Fig. 4). The mean date for onset of reproductive neuroendocrine quiescence was 19 October \pm 6.6 days, with reproductive activity resuming again on 20 December \pm 1.9 days. However, in all THX negative control hinds, $\mathrm{LH}$ concentrations remained high throughout the summer so that reproductive quiescence could not be detected. A similar pattern was observed for $\mathrm{THX}+$ early $\mathrm{T}_{4}$ hinds. In three of the five $\mathrm{THX}+$ mid- $_{4}$ hinds, the dates of onset of reproductive quiescence were not different from those of euthyroid controls (18 October for all three hinds; $P>0.05$ ); however, $\mathrm{LH}$ concentrations returned to $>1 \mathrm{ng} \mathrm{ml}{ }^{-1}$ within 2-3 weeks in two of these hinds ( 1 and 8 November) while remaining low until 23 December in the third hind (which had plasma tri-iodothyronine concentrations 2-3 times higher than others in this group). In the remaining two $\mathrm{THX}+$ mid- $\mathrm{T}_{4}$ hinds (in which plasma tri-iodothyronine concentrations averaged $0.1 \mathrm{nmol}^{-1}$; the lowest of all thyroxinetreated hinds), reproductive quiescence was not recorded despite a decrease in $\mathrm{LH}$ concentrations around this time. Reproductive quiescence occurred significantly later than for euthyroid controls in four THX+late $\mathrm{T}_{4}$ hinds (17 December \pm 2.5 days; $P<0.001$ ); in the remaining hind, reproductive quiescence was not detected, although a decrease in LH concentrations occurred. Reproductive activity resumed on 27 January and 3 February for two of the four hinds in which quiescence occurred, but $\mathrm{LH}$ was still suppressed in the other two hinds at the end of the experiment (10 February).

Data for pulsatile LH secretion during July and November are shown (Table 2). The mean number of $\mathrm{LH}$ pulses was lower in November than in July in euthyroid control hinds $(P<0.001)$ and in the THX + mid- $\mathrm{T}_{4}$ hind that had low $\mathrm{LH}$ concentrations from October until December (no pulses were detected over the $4 \mathrm{~h}$ sampling period in November in this hind). In all other hinds, the number of pulses did not differ significantly between July and November $(P>0.05)$, while pulse amplitude increased in November $(P<0.05)$.

In all hinds, there was a seasonal change in pituitary responsiveness to exogenous $\mathrm{GnRH}$, with maximal responsiveness $\left(38.3 \pm 2.8 \mathrm{ng} \mathrm{ml}^{-1}\right)$ occurring during late July (breeding season) and minimal responsiveness in November and December (non-breeding season), although responsiveness was also low during thyroxine implantation in February in $\mathrm{THX}+$ late $\mathrm{T}_{4}$ hinds $(9.2 \pm 2.6)$ compared with $\mathrm{THX}+$ early $\mathrm{T}_{4}(19.6 \pm 3.3)$ and $\mathrm{THX}+$ mid-T $_{4}(24.6 \pm 3.4)$ hinds $(P<0.05)$. Pituitary LH response to GnRH during November and December was lower in euthyroid control hinds (average of both months: $6.6 \pm 1.1 \mathrm{ng} \mathrm{ml} \mathrm{ml}^{-1}$ ) than in all other groups (average: $\left.15.4 \pm 1.2 \mathrm{ng} \mathrm{ml}^{-1}\right)(P<0.05)$. At all other times of the year, $\mathrm{LH}$ responses to $\mathrm{GnRH}$ were not significantly different among groups.

\section{Discussion}

To our knowledge, the results of Expt 1 are the first published report to show that the cessation of oestrous cyclicity during the non-breeding season is dependent on the presence of thyroid hormones. This is supported by the findings of Nicholls et al. (1988), which showed that thyroidectomy prevented the cessation of oestrous cyclicity in ewes induced by long photoperiods or by development of refractoriness to equatorial photoperiods, and of other researchers who have used thyroid hormone replacement experiments to demonstrate a requirement for thyroid hormones for the seasonal onset of steroid-dependent suppression of LH concentrations in ewes (Webster et al., 1991b; Thrun ef al., 1996) and testicular regression and associated changes in red deer stags (Shi and Barrell, 1994). Experiments 2 and 3 extended this finding by showing that, in red deer hinds, the effects of thyroid hormones are directed specifically at the steroid-independent component of the mechanism regulating seasonal breeding. This differs from the situation in ewes, in which thyroid hormones appear to be required to initiate the negative feedback influence of oestradiol on reproductive neuroendocrine activity during anoestrus (Webster et al., 1991b); that is, their effect is directed at the steroid-dependent component.

There are relatively few published reports of the effects of thyroidectomy on oestrous cyclicity in any species. Thyroidectomy has been shown not to affect the steroid feedback responses required for generation of the preovulatory LH surge or for suppression of ovulation during the luteal phase in ewes during the breeding season (Webster et al., 1991b). Nicholls et al. (1988) showed that ewes thyroidectomized just before the breeding season initiated cycles at the same time as control animals, but continued to cycle for more than 1 year and were still cyclic when general debilitation necessitated termination of the experiment. There may be species differences in the requirement of thyroid hormones for oestrous cyclicity since, in two separate studies, thyroidectomy or suppression of thyroid function in female goats has been shown to impair or even abolish normal ovarian function (Reddy et al., 1996; WalkdenBrown et al., 1996). Although the present results indicate that this is not the case for red deer, it should be noted that many of the progesterone episodes seen in THX and THX $+\mathrm{T}_{4}$ hinds were shorter in duration than those of euthyroid hinds and irregular in occurrence, suggesting a possible role for thyroid gland secretions other than thyroxine or its metabolite triiodothyronine for normal ovarian function. Nevertheless, normal mating, conception and pregnancy have been recorded in at least five thyroidectomized hinds (G. M. Anderson and G. K. Barrell, unpublished), indicating that if such a role exists it is not an absolute requirement for successful breeding in this species. 


\begin{tabular}{|l|l|l|}
\hline Early $\mathrm{T}_{4}$ & Mid-T & Late $\mathrm{T}_{4}$ \\
\hline
\end{tabular}

(a)

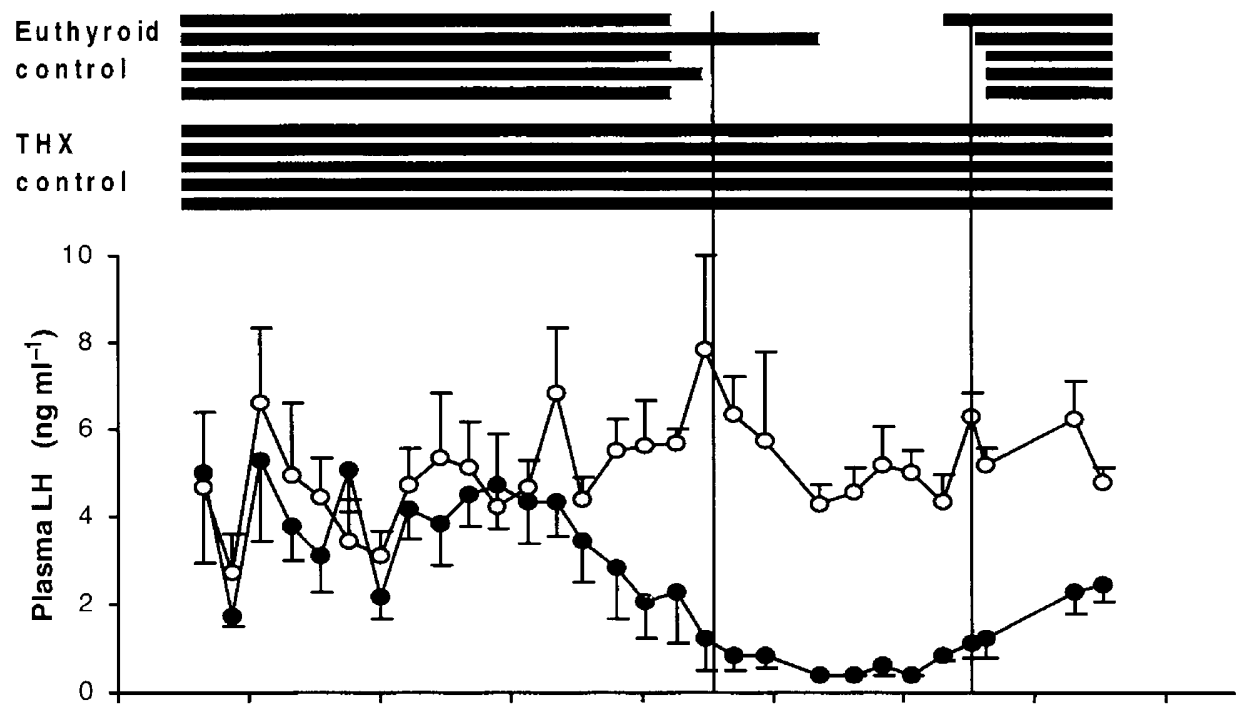

(b)

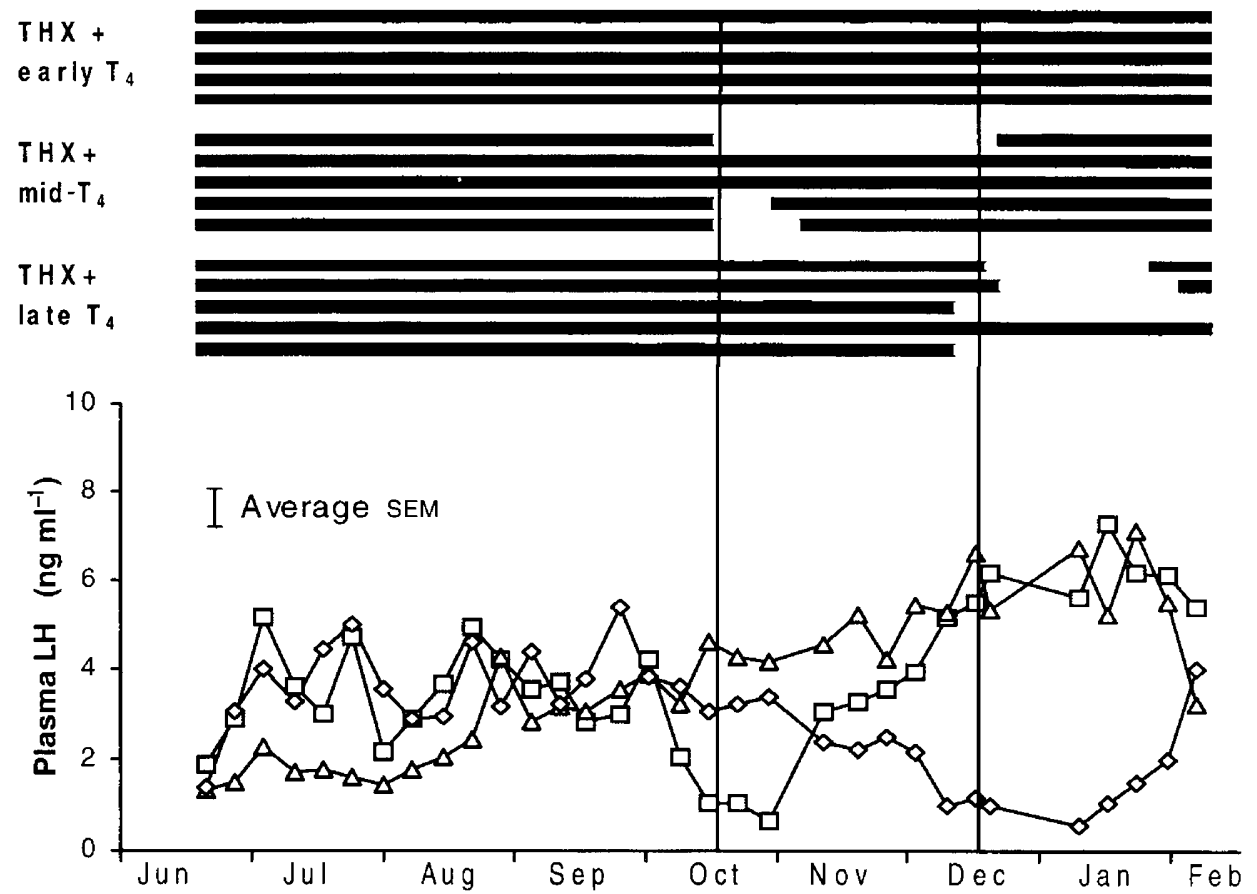

Fig. 4. Mean ( \pm SEM) plasma concentrations of LH in (a) euthyroid control ( $)$ and thyroidectomized $(\mathrm{THX}$ ) control (O) red deer hinds, and (b) hinds thyroidectomized and treated with subcutaneous thyroxine implants at different times (THX + early $\mathrm{T}_{4}: \triangle$; THX + mid- $T_{4}$ : $\square$; and $T H X+$ late $T_{4}$ hinds: $\diamond)(n=5)$. Horizontal lines indicate times when individual hinds were defined as being reproductively active. Vertical lines indicate the mean period of reproductive quiescence in euthyroid positive control hinds. Periods of thyroxine replacement are indicated at the top of the figure.

Replacement of thyroid hormones to physiological concentrations in Expt 1 restored the seasonal pattern of oestrous cyclicity in thyroidectomized hinds to that of euthyroid control hinds. This finding confirms that the effects of thyroidectomy are due to the absence of thyroid hormones. The gradual increase in plasma tri-iodothyronine concentrations in the 
Table 2. LH pulse characteristics in ovariectomized female red deer during $4 \mathrm{~h}$ intensive sampling periods in July (breeding season) and November (non-breeding season) (Expt 3)

\begin{tabular}{lccccc}
\hline & \multicolumn{2}{c}{ Number in $4 \mathrm{~h}$} & & \multicolumn{2}{c}{ Amplitude } \\
\cline { 2 - 3 } \cline { 5 - 5 } Group & July & November & & July & November \\
\hline Euthyroid control & $4.0 \pm 0.3$ & $1.0 \pm 0.4^{* *}$ & & $3.3 \pm 1.3$ & $1.1 \pm 0.4$ \\
$\mathrm{THX}$ control & $3.0 \pm 0.7$ & $3.0 \pm 0.4$ & & $3.3 \pm 0.8$ & $14.5 \pm 1.9^{* *}$ \\
$\mathrm{THX}+$ early $\mathrm{T}_{4}$ & $2.4 \pm 0.4$ & $2.5 \pm 0.5^{\dagger}$ & & $4.9 \pm 1.7$ & $8.3 \pm 2.0^{*}$ \\
$\mathrm{THX}+$ mid- $\mathrm{T}_{4}$ & $2.4 \pm 0.6$ & $2.8 \pm 0.7$ & & $1.5 \pm 0.5$ & $11.1 \pm 2.1^{* *}$ \\
$\mathrm{THX}+$ late $\mathrm{T}_{4}$ & $2.4 \pm 0.2$ & $3.8 \pm 0.8$ & & $2.7 \pm 0.6$ & $7.7 \pm 1.6^{*}$ \\
\hline
\end{tabular}

Significantly different between seasons: ${ }^{*} P<0.05 ;{ }^{* *} P<0.001$.

${ }^{+}$Data from one hind with no detectable pulses are excluded from this mean (see text for details).

THX: thyroidectomized; $\mathrm{T}_{4}$ : thyroxine.

thyroid hormone-replaced hinds in this experiment was probably caused by the repeated thyroxine administration rather than by seasonal changes in cardiac output or peripheral circulation, since a single thyroxine implantation of the same dose in Expt 3 resulted in a comparatively low plasma tri-iodothyronine concentration regardless of the time of year. It could be argued that the cessation of oestrous cycles in the thyroid hormone-replaced hinds was driven by the increasing concentrations of the exogenously administered thyroxine, rather than being permitted by the mere presence of thyroid hormones. The premature termination of the breeding season in ewes injected with large doses of thyroxine ( $\mathrm{O}^{\prime}$ Callaghan et al., 1993) and its extension in ewes with suppressed thyroid secretion (Follett and Potts, 1990) lend some support to this possibility. However, recent studies in which thyroid hormone concentrations have been manipulated approximately within the normal physiological range have failed to alter the timing of the non-breeding season in either ewes (Dahl et al., 1995) or red deer stags (Shi and Barrell, 1994). Since the thyroxine implants in Expt 1 produced very similar circulating thyroxine and tri-iodothyronine concentrations to those seen in euthyroid animals, it is unlikely, in the light of the aforementioned studies, that the onset of anoestrus was due to the gradual increase in concentrations of exogenously administered thyroid hormones.

An intriguing finding from Expt 2 is the striking similarity of LH profiles in ovariectomized control and thyroidectomized hinds in the presence of oestradiol. LH concentrations in plasma of thyroidectomized hinds in Expt 2 were profoundly suppressed by oestradiol during the period of the year corresponding to the non-breeding season of intact, non-pregnant hinds. This is in marked contrast to the growing body of evidence for ewes (for example, Moenter et al., 1991; Webster ef al., 1991b), in which it has been demonstrated that the thyroid gland is required for oestradiol-induced suppression of $\mathrm{LH}$ concentrations. It is possible that the low plasma $\mathrm{LH}$ concentrations in the THX hinds in the present study merely reflect profound suppression by oestradiol at the pituitary gland (see Baker et al., 1995; Meikle and Fisher, 1996), even though pulsatile GnRH secretion remains high, as is known to occur in thyroidectomized ewes (Webster et al., 1991a). However, this is unlikely for two reasons. First, exogenous GnRHinduced LH concentrations in thyroidectomized hinds did not decrease until October, whereas basal LH concentrations declined in August (Fig 3), so a loss of pituitary responsiveness to $\mathrm{GnRH}$ cannot account for the low basal LH concentrations in the intervening period. Second, the number of LH pulses detected over the $4 \mathrm{~h}$ intensive sampling period in late October was reduced in thyroidectomized, oestradiol-treated hinds, indicating that the effect was on GnRH pulse generation, since $\mathrm{GnRH}$ and LH pulses are temporally (and presumably causally) coupled (Clarke and Cummins, 1982; Levine et al., 1982; Karsch et al., 1987, 1993; Barrell et al., 1992).

The increased plasma LH concentrations in thyroidectomized hinds relative to control animals in the absence of oestradiol during November indicate that there is a major species difference between sheep and deer in the mode of action of thyroid hormones on regulation of seasonal breeding cycles. From this result, it can be argued that thyroid hormones are required specifically for the steroid-independent component of seasonal reproductive regulation that transiently but profoundly suppresses plasma LH concentrations around the time of the summer solstice in this species (Meikle and Fisher, 1996). This finding was confirmed and extended by the results of Expt 3, which also showed that pulsatile LH secretion remains high in thyroidectomized, ovariectomized hinds relative to euthyroid controls during November (non-breeding season).

The results of Expt 3 demonstrate that thyroid hormones have a season-specific role in mediating the steroidindependent suppression of plasma LH concentrations in red deer hinds since thyroxine replacement in thyroidectomized hinds during the breeding season did not initiate this suppression, whereas thyroxine replacement applied around and after the end of the breeding season did initiate suppression. The results of the present study confirm recent findings in ewes that demonstrated that thyroid hormones need only be present for a short time before the end of the breeding season to permit the seasonal decrease in LH concentrations (Thrun et al., 1996, 1997); they also extend these findings by demonstrating that red deer hinds remain capable of responding to thyroid hormones for at least 40 days after the breeding season. Because thyroxine replacement af the latest date in the present study caused neuroendocrine reproductive quiescence, the period of responsiveness to thyroid hormones must extend to, and beyond, this time. Therefore, we were unable to define the offset of this period. The present results suggest that, if there is 
such a window of neuroendocrine responsiveness, it begins less than 40 days before the transition to the non-breeding season and extends beyond this transition for an as yet unknown period.

Only three of five hinds that received thyroxine replacement around the end of the breeding season (August to October) entered reproductive quiescence, and the duration of quiescence was brief ( $2-3$ weeks) in two of these hinds, indicating that the transition to the reproductively inactive state had not been totally achieved. However, the thyroid hormone concentrations achieved by this mid-thyroxine treatment were probably at the margin of those required to restore normal seasonal reproductive patterns to those seen in euthyroid control hinds. This suggestion is corroborated by the observation that the one hind in which duration of suppression of LH concentrations and pulsatile secretion of LH in November was similar to that of euthyroid control hinds had the highest triiodothyronine concentrations for the group (mean $0.5 \mathrm{nmol}$ $\left.\mathrm{I}^{-1}\right)$, and the two hinds in which LH was not completely suppressed had barely detectable plasma concentrations of tri-iodothyronine (mean: $0.1 \mathrm{nmol} \mathrm{l}^{-1}$ ); these were the lowest concentrations recorded from any of the thyroxine-treated hinds while the implants were in place. These low triiodothyronine concentrations equate approximately to $5 \mathrm{nmol}$ thyroxine $\mathrm{l}^{-1}$ (assuming a 50:1 total thyroxine:total triiodothyronine ratio based on the results of Expt 1) which is close to the minimum threshold concentration of $2 \mathrm{nmol}$ thyroxine $1^{-1}$ estimated to be required for achieving anoestrus in sheep (Thrun et al., 1997). All five hinds in the THX + mid- $\mathrm{T}_{4}$ group showed a decline in plasma LH concentrations during October. It is likely that much of the variation in response to thyroxine treatment before October can be explained by the circulating thyroid hormone concentrations achieved by the implants being near to threshold amounts in some animals.

The results of this study suggest that the mechanisms that suppress plasma LH concentration in ovariectomized hinds are responsive to thyroid hormones only when the prevailing photoperiods or the endogenous reproductive rhythm are inhibitory to reproductive activity, since thyroxine replacement during inductive short photoperiods (that is, the THX + early $\mathrm{T}_{4}$ group) caused no reproductive suppression, whereas thyroxine replacement during inhibitory long or increasing photoperiods (that is, the THX + late $\mathrm{T}_{4}$ and $\mathrm{THX}+$ mid- $\mathrm{T}_{4}$ groups) $\mathrm{did}$. If this is the case, the 'window' of responsiveness to the inhibitory influence of thyroid hormones under natural conditions would be expected to continue throughout the summer until the endogenous signalling mechanisms and decreasing photoperiods signal the next breeding season. In support of this concept, treatment of thyroidectomized red deer stags with thyroxine implants or even a single injection of triiodothyronine during summer caused the cessation of rutting behaviour and antler casting (G. M. Anderson, unpublished), and rams exhibit a reproductive response to removal of the thyroid glands during the non-breeding season (Parkinson and Follett, 1994). The recent finding that thyroxine replacement of thyroidectomized ewes about 1 month before the onset of the breeding season in autumn (when photoperiods are decreasing) did not cause serum LH concentrations to decrease (Thrun et al, 1997) lends further support to the argument that thyroid hormones exert their action only during inhibitory photo- periods and the appropriate phase of the endogenous rhythm. An important underlying assumption here is that thyroidectomy does not prevent neuroendocrine perception of photoperiodic changes or generation of the endogenous reproductive rhythm, but that it is the normal response of the hypothalamohypophysial axis to these stimuli that is disrupted. It has been demonstrated by appropriate prolactin and melatonin responses to fluctuating photoperiods in thyroidectomized animals that thyroidectomy does not disrupt sensitivity to photoperiodic stimuli (Jacquet et al., 1986; Nicholls et al., 1988; Moenter et al., 1991; Shi and Barrell, 1992; Dahl et al., 1994a). The existence of an endogenous rhythm of reproductive function in thyroidectomized animals could be confirmed unequivocally only by maintaining animals under long-term fixed photoperiods (or pinealectomizing them) and treating them with thyroid hormones at different times of the year.

To our knowledge, the present results are the first to describe episodic LH secretion in ovariectomized hinds during the period of reproductive quiescence. In euthyroid hinds, pulse frequency was low at this time (November) compared with during the breeding season. This finding is also the case in ovariectomized ewes (Karsch et al., 1980; Goodman et al, 1982; Robinson et al., 1985; Moenter et al., 1991), although the magnitude of the seasonal change is much greater in hinds. Ovariectomized ewes show an increase in LH pulse amplitude during the non-breeding season (Karsch et al., 1980; Goodman et al., 1982; Moenter et al., 1991), whereas, in hinds, pulse amplitude decreased, albeit non-significantly, during the non-breeding season of red deer. The role of thyroid hormones in steroidindependent seasonal LH secretion in ewes has received no direct attention; however, the results of Moenter et al. (1991) suggest that $\mathrm{LH}$ pulse frequency and amplitude remain at breeding season values in thyroidectomized, ovariectomized ewes during the non-breeding season. Thyroidectomy prevented the seasonal decrease in LH pulse frequency in the hinds in our experiment but, in addition, caused pulse amplitude to increase approximately fourfold compared with breeding season amplitudes. One possible explanation for this is that high amplitude pulses of $\mathrm{GnRH}$ may occur in hinds during the non-breeding season, but correspondingly large LH pulses are prevented owing to the seasonal decrease in responsiveness of the anterior pituitary gland to GnRH (Meikle and Fisher, 1996; Expt 2). Since this seasonal decrease in pituitary responsiveness was greatly diminished in the absence of the thyroid glands (see discussion below), high amplitude LH pulses could be expressed in thyroidectomized hinds. Methods for collecting portal blood and measuring GnRH have not been developed in our laboratory, so we are not able to test this hypothesis directly.

The results for episodic LH secretion confirm that, in November, all hinds except euthyroid controls and a single $\mathrm{THX}+$ mid- $_{4}$ treated hind were equivalent to being reproductively active, since pulse frequency remained high at this time. Presumably, if sampling for pulsatile LH secretion had been conducted earlier in November while most of the THX + mid$\mathrm{T}_{4}$ group were still reproductively suppressed, this may have provided further confirmation of their responsiveness to thyroid hormones around the end of the breeding season. Similarly, it may have been of value to have monitored pulsatile LH secretion in January after the decrease in mean plasma $\mathrm{LH}$ concentrations in $\mathrm{THX}+$ late $\mathrm{T}_{4}$ treated hinds. 
The stimulatory effect of thyroidectomy on pulsatile secretion of LH in ovariectomized hinds during November indicates that thyroid hormones may modify the output of the hypothalamic GnRH neurones (Clarke and Cummins, 1982; Levine et al., 1982; Karsch et al., 1993). Therefore, the maintenance of high LH concentrations throughout the summer after thyroidectomy in Expt 3 probably reflects a continuation of increased episodic GnRH secretion during this period, as has been shown to occur in ewes (Webster et al., 1991a). The observation that thyroid hormone receptors are present in neuroendocrine tissues, including GnRH neurones (Jansen et al., 1994), and the demonstration that thyroid hormones can act centrally to alter hypothalamic secretions (Dahl et al., 1994b), support this view. In Expts 2 and 3 and in another study involving red deer stags (Shi and Barrell, 1992), evidence was also obtained for an effect of thyroidectomy on the pituitary gland since, in THX hinds, the seasonal decrease in LH release after a GnRH challenge during November was markedly reduced (although not completely abolished). An effect of thyroid hormones in deer at the anterior pituitary gland may represent another difference in the mode of thyroid hormone action between red deer and sheep since, in sheep, the responsiveness of the anterior pituitary gland to GnRH exhibits very little or no seasonal variation (for example, see Jenkin et al., 1977; Brewer et al., 1995). In THX + late $\mathrm{T}_{4}$ hinds in Expt 3, pituitary responsiveness to GnRH was also low in February relative to $\mathrm{THX}+$ early $\mathrm{T}_{4}$ and $\mathrm{THX}+$ mid $^{-\mathrm{T}_{4}}$ hinds. This finding may reflect a delayed response to thyroxine treatment, as was observed for basal $\mathrm{LH}$ concentrations, although the time taken to respond to thyroxine was much greater for pituitary responsiveness than for basal LH. Collectively, these observations imply that thyroid hormones act in a different way and have a different response time at the pituitary than they do centrally.

It could be argued that the absence of a seasonal suppression of pituitary responsiveness may be the mechanism by which basal LH plasma concentrations remain high in ovariectomized thyroidectomized hinds. However, this seems unlikely since, in Expt 3, LH pulse frequency also remained high during the non-breeding season in ovariectomized, thyroidectomized hinds relative to euthyroid controls, indicating a high frequency of GnRH pulses (Clarke and Cummins, 1982; Levine et al., 1982; Karsch et al., 1993). In thyroidectomized hinds, oestradiol appears to retain the ability to suppress reproductive neuroendocrine function during the non-breeding season at both the hypothalamus and the anterior pituitary. It is possible that the effects of thyroidectomy on steroid-independent pathways were masked by the potent steroid-dependent suppression of LH concentration while oestradiol was present in Expt 2 but that, in the ovary-intact hinds in Expt 1, endogenous oestrogen secretion was low enough to allow the steroidindependent effects to be manifest as a continuation of oestrous cyclicity throughout the non-breeding season. In this regard, a limitation of Expt 2 is our current inability to measure oestradiol reliably in deer plasma, and hence to verify that the concentration produced by an implant is within the normal physiological range.

Differences in the degree of gonadotrophin suppression exerted by steroid-independent mechanisms are known to exist among various species and breeds of birds and mammals (for example, Gibson et al., 1975; Garcia and Ginther, 1976; Lincoln and Kay, 1979; Lincoln and Short, 1980; McLeod et al., 1996). It has been suggested that these differences may reflect the degree of domestication (Goodman and Karsch, 1981), since seasonal gonadotrophin fluctuations in the absence of gonadal steroids are greater in the Soay ram, a relatively undomesticated breed (Lincoln and Short, 1980), compared with the domestic Suffolk ewe (for example, see Robinson et al., 1985). As red deer have been introduced to the farm environment only within the last 30 years (Fisher and Bryant, 1993), their reproductive neuroendocrine function may be more akin to that of relatively undomesticated animals. The results of the present study indicate that the thyroidectomized, ovariectomized red deer hind offers an unique and interesting animal model for studying the relative roles of steroid-dependent and steroid-independent mechanisms of gonadotrophin suppression.

In conclusion, the results presented here do not fit into the commonly proposed model for regulation of seasonal breeding in domestic ewes whereby steroid-dependent regulation is considered to be the major determinant of seasonality. Rather, the overall finding that the transition to anoestrus in red deer hinds can be prevented by thyroidectomy, a treatment that appears to disrupt steroid-independent but not steroiddependent processes, leads us to speculate that steroidindependent mechanisms may be at least as important in regulating seasonal breeding as steroid-dependent mechanisms in this species. Furthermore, the present results do not support the existence of a brief window of neuroendocrine responsiveness to thyroid hormones that operates only around the end of the breeding season in red deer hinds, since exposure to thyroxine starting about 6 weeks after this time brought about suppression of plasma LH concentration.

Grateful thanks are extended to M. J. Keeley for assistance with animal handling and sample collection, and to Elanco Animal Health for donation of the Compudose implants. LH assay reagents were provided by A. F. Parlow, Pituitary Hormones and Antisera Center, Torrance, CA. Funding for this research was provided by the Lottery Science Research Committee of the New Zealand Lottery Grants Board and the Canterbury Branch of the New Zealand Deer Farmers Association. Many of the animals used in these experiments were kindly provided by the Canterbury Branch of the New Zealand Deer Farmers Association.

\section{References}

Adam CL, Moir CE and Atkinson T (1985) Plasma concentrations of progesterone in female red deer (Cervus elaphus) during the breeding season, pregnancy and anoestrus Journal of Reproduction and Fertility 74 631-636

Baker DL, Miller MW and Nett TM (1995) Gonadotropin-releasing hormone analog-induced patterns of luteinizing hormone secretion in female wapiti (Cervus elaphus nelsoni) during the breeding season, anestrus, and pregnancy Biology of Reproduction 52 1193-I197

Barrell GK, Moenter SM, Caraty A and Karsch FJ (1992) Seasonal changes of gonadotropin-releasing hormone secretion in the ewe Biology of Reproduction 46 1130-I135

Brewer JC, Briggs RM, Parr J, Wilkins RJ and Smith JF (1995) Effect of selection for early lambing performance on the seasonal patterns of gonadotrophin levels, response to $\mathrm{GnRH}$ and semen characteristics in adult rams Proceedings of the New Zealand Society of Animal Production 55 228-231

Clarke IJ and Cummins JT (1982) The temporal relationship between gonadotrophin releasing hormone $(\mathrm{GnRH})$ and luteinizing hormone (LH) secretion in ovariectomized ewes Endocrinology 111 1737-1739 
Dahl GE, Evans NP, Moenter SM and Karsch FJ (1994a) The thyroid gland is required for reproductive neuroendocrine responses to photoperiod in the ewe Endocrinology 135 10-15

Dahl GE, Evans NP, Thrun LA and Karsch FJ (1994b) A central negative feedback action of thyroid hormones on TRH secretion Endocrinology 135 2392-2397

Dahl GE, Evans NP, Thrun LA and Karsch FJ (1995) Thyroxine is permissive to seasonal transitions in reproductive neuroendocrine activity in the ewe Biology of Reproduction 52 690-696

Elder PA, Yeo KHJ, Lewis JG and Clifford JK (1987) An enzyme-linked immunosorbant assay (ELISA) for plasma progesterone: immobilised antigen approach Clinica Chimica Acta 162 199-206

Fisher MW and Bryant LD (1993) What might be the consequences of adapting wild animals such as wapiti to a farm environment? Proceedings of the New Zealand Society of Animal Production 53 457-460

Follett BK and Nicholls TJ (1985) Influences of thyroidectomy and thyroxine replacement on photoperiodically controlled reproduction in quail Journal of Endocrinology $107211-221$

Follett BK and Potts C (1990) Hypothyroidism affects reproductive refractoriness and the seasonal oestrous period in Welsh Mountain ewes Journal of Endocrinology 127 103-109

Garcia MC and Ginther OJ (1976) Effects of ovariectomy and season on plasma luteinizing hormone in mares Endocrinology 98 958-962

Gibson WR, Follett BK and Gledhill B (1975) Plasma levels of luteinizing hormone in gonadectomized Japanese quail exposed to short or to long daylengths Journal of Endocrinology 64 87-101

Goldsmith AR and Nicholls TJ (1984) Thyroidectomy prevents the development of photorefractoriness and the associated rise in plasma prolactin in starlings General and Comparative Endocrinology 54 256-263

Goodman RL and Karsch FJ (1980) Pulsatile secretion of luteinizing hormone: differential suppression by ovarian steroids Endocrinology 107 1286-1289

Goodman RL and Karsch FJ (1981) A critique of the evidence on the importance of steroid feedback to seasonal changes in gonadotrophin secretion joumal of Reproduction and Fertility Supplement 30 1-13

Goodman RL, Bittman EL, Foster DL and Karsch FJ (1982) Alterations in the control of luteinizing hormone pulse frequency underlie the seasonal variation in estradiol negative feedback in the ewe Biology of Reproduction $\mathbf{2 7}$ $580-589$

Jacquet J-M, Coutant C, Maurel D, Boissin-Agasse L and Boissin J (1986) Influence de la thyrö̈dectomie sur les variations, au cours du printemps et de l'été de l'activité testiculaire et de la prolactinémie chez le vison Comptes Rendus des Seances de L'Acadamie des Sciences, Paris (III) 303 367-370

Jansen HT, Lubbers LS, DeGroot LJ and Lehman MN (1994) Co-localization of $\alpha$-thyroid hormone receptors in neuropeptide-and neurotransmittercontaining neurons of the sheep and hamster brain Biology of Reproduction 50 (Supplement 1) Abstract 213

Jenkin G, Heap RB and Symons DBA (1977) Pituitary responsiveness to synthetic LH-RH and pituitary LH content at various reproductive stages in sheep Journal of Reproduction and Fertility 49 207-214

Jopson NB, Fisher MW and Suttie JM (1990) Plasma progesterone concentrations in cycling and ovariectomized red deer hinds; the effect of progesterone supplementation and adrenal stimulation Animal Reproduction Science 23 61-73

Karsch FJ, Goodman RL and Legan SJ (1980) Feedback basis of seasonal breeding: test of an hypothesis Journal of Reproduction and Fertility $\mathbf{5 8}$ 521-535

Karsch FJ, Cummins JT, Thomas GB and Clarke IJ (1987) Steroid feedback inhibition of pulsatile secretion of gonadotropin-releasing hormone in the ewe Biology of Reproduction 36 1207-1218

Karsch FJ, Dahl GE, Evans NP, Manning JM, Mayfield KP, Moenter SM and Foster DL (1993) Seasonal changes in gonadotropin-releasing hormone secretion in the ewe: alteration in response to the negative feedback action of estradiol Biology of Reproduction 49 1377-1383

Karsch FJ, Dahl GE, Hachigian TM and Thrun LA (1995) Involvement of thyroid hormones in seasonal reproduction Journal of Reproduction and Fertility Supplement 49 409-422

Kelly RW, McNatty KP, Moore GH, Ross O and Gibb M (1982) Plasma concentrations of $\mathrm{LH}$, prolactin, oestradiol and progesterone in female red deer (Cerous elaphus) during pregnancy Journal of Reproduction and Fertility 64 $475-483$

Levine JE, Pau K-YF, Ramirez VD and Jackson GL (1982) Simultaneous measurement of luteinizing hormone releasing hormone and luteinizing hormone release in unanesthetized sheep Endocrinology 111 1449-1455
Lincoln GA and Kay RNB (1979) Effects of season on the secretion of LH and testosterone in intact and castrated red deer stags (Cervus elaphus) Journal of Reproduction and Fertility $\mathbf{5 5} 75-80$

Lincoln GA and Short RV (1980) Seasonal breeding: nature's contraceptive Recent Progress in Hormone Research 36 1-52

McLeod BJ, Kyle SE and Ramsay MR (1996) Seasonal changes in FSH and LH concentrations in ewes with gonadal hypoplasia: evidence that steroidindependent mechanisms control seasonality in sheep? Proceedings of the New Zealand Society of Animal Production 56 367-369

Meikle LM and Fisher MW (1996) The regulation of pronounced seasonality in the red deer hind: oestradiol-dependent and independent influences on the pattern of LH and prolactin secretion Journal of Reproduction and Fertility 106 213-220

Moenter SM, Woodfill CJI and Karsch FJ (1991) Role of the thyroid gland in seasonal reproduction: thyroidectomy blocks seasonal suppression of reproductive neuroendocrine activity in ewes Endocrinology 128 1337-1344

Nicholls TJ, Follett BK, Goldsmith AR and Pearson H (1988) Possible homologies between photorefractoriness in sheep and birds: the effect of thyroidectomy on the length of the ewe's breeding season Reproduction, Nutrition, Développement $28 \quad 375-385$

O'Callaghan D, Wendling A, Karsch FJ and Roche JF (1993) Effect of exogenous thyroxine on timing of seasonal reproductive transitions in ewes Biology of Reproduction 49 311-315

Parkinson TJ and Follett BK (1994) Effect of thyroidectomy on seasonality in rams Journal of Reproduction and Fertility 101 51-58

Pau K-YF and Jackson GL (1985) Effect of frontal hypothalamic deafferentation on photoperiod-induced changes of luteinizing hormone secretion in the ewe Neuroendocrinology 41 72-78

Reddy IJ, Varshney VP, Sanwal PC, Agarwal N and Pande JK (1996) Peripheral plasma oestradiol-17 $\beta$ and progesterone levels in female goats induced to hypothyroidism Small Ruminant Research 22 149-154

Robinson JE, Radford HM and Karsch FJ (1985) Seasonal changes in pulsatile luteinizing hormone ( $\mathrm{LH}$ ) secretion in the ewe: relationship of frequency of LH pulses to day length and response to estradiol negative feedback Biology of Reproduction 33 324-334

Scaramuzzi RJ, Caldwell BV and Moor RM (1970) Radioimmunoassay of LH and estrogen during the estrous cycle of the ewe Biology of Reproduction 3 110-119

Shi ZD and Barrell GK (1992) Requirement of thyroid function for the expression of seasonal reproductive and related changes in red deer (Cervus elaphus) stags Journal of Reproduction and Fertility 94 251-259

Shi ZD and Barrell GK (1994) Thyroid hormones are required for the expression of seasonal changes in red deer (Cervus elaphus) stags Reproduction Fertility and Development 6 187-192

Simpson AM, Suttie JM and Kay RNB (1983) The influence of artificial photoperiod on the growth, appetite and reproductive status of male red deer and sheep Animal Reproduction Science 6 291-299

Thrun LA, Dahl GE, Evans NP and Karsch FJ (1996) Time-course of thyroid hormone involvement in the development of anestrus in the ewe Biology of Reproduction 55 833-837

Thrun LA, Dahl GE, Evans NP and Karsch FJ (1997) A critical period for thyroid hormone action on seasonal changes in reproductive neuroendocrine function in the ewe Endocrinology 138 3402-3409

Vriend J (1985) Effects of melatonin and thyroxine replacement on thyrotropin, luteinizing hormone and prolactin in male hypothyroid hamsters Endocrinology 117 2402-2407

Walkden-Brown SW, Davidson RH, Milton JTB and Martin GB (1996) Thyroidectomy late in the breeding season advances the onset of seasonal anovulation in cashmere goats 13 th International Congress on Animal Reproduction Abstract P1-19

Webster JR and Barrell GK (1985) Advancement of reproductive activity, seasonal reduction in prolactin secretion and seasonal pelage changes in pubertal red deer hinds (Cervus elaphus) subjected to artificially shortened daily photoperiod or daily melatonin treatments journal of Reproduction and Fertility 73 255-260

Webster JR, Moenter SM, Barrell GK, Lehman MN and Karsch FJ (1991a) Role of the thyroid gland in seasonal reproduction III. Thyroidectomy blocks seasonal suppression of gonadotropin-releasing hormone secretion in sheep Endocrinology 129 1635-1643

Webster JR, Moenter SM, Woodfill CJI and Karsch FJ (1991b) Role of the thyroid gland in seasonal reproduction II. Thyroxine allows a season-specific suppression of gonadotropin secretion in sheep Endocrinology 129 176-183 